\title{
Quality of life of patients with chronic obstructive pulmonary disease treated with indacaterol and/or glycopyrronium: a real-world Polish observational study
}

Tadeusz Płusa

Faculty of Medicine, Lazarski University of Warsaw, Warsaw, Poland

Submitted: 18 November 2018

Accepted: 29 November 2018

Arch Med Sci Civil Dis 2018; 3: e202-e209

DOI: https://doi.org/10.5114/amscd.2018.81306

Copyright (c) 2018 Termedia \& Banach

\section{Abstract}

Introduction: The aim of this study was to evaluate the impact of routinely administered treatment with indacaterol and/or glycopyrronium on quality of life and level of dyspnoea of patients with chronic obstructive pulmonary disease (COPD) in a real-life setting.

Material and methods: It was an observational, non-interventional study in patients with stable, symptomatic chronic obstructive pulmonary disease initiating treatment with indacaterol and/or glycopyrronium as part of routine care. The primary outcomes included a change in quality of life measured using the Clinical COPD Questionnaire (CCQ) and level of dyspnoea evaluated using the modified Medical Research Council scale (mMRC). Patients were followed up for 6 months after initiation of treatment.

Results: Analysis included baseline data from 586 patients. At 6 months $82.5 \%(n=483)$ of patients were continuing initiated treatment. Improvement of $\mathrm{mMRC}$ and CCO scores was observed in all treatment arms. The mean total CCQ score \pm SD changed after 6 months from $2.2 \pm 0.9$ to $1.2 \pm 0.9$ in the indacaterol group $(p<0.001)$, from $2.1 \pm 1.0$ to $1.0 \pm 0.9(p<0.001)$ in the glycopyrronium group and $2.6 \pm 1.1$ at baseline to $1.3 \pm 1.0(p<0.001)$ in the indacaterol/glycopyrronium group. The mean $\mathrm{mMRC} \pm \mathrm{SD}$ decreased from $2.1 \pm 0.9$ to $1.4 \pm 0.9(p<0.001)$ in the indacaterol group, from $2.1 \pm 0.9$ to $1.2 \pm 1.0(p<0.001)$ in the glycopyrronium group, and from $2.3 \pm 0.8$ to 1.4 \pm 0.9 ( $p<0.001)$ in the indacaterol/glycopyrronium group.

Conclusions: Use of indacaterol and/or glycopyrronium improved quality of life and breathlessness in patients with stable COPD, efficiently reducing the symptoms burden.

Key words: quality of life, chronic obstructive pulmonary disease, indacaterol, glycopyrronium.

\section{Introduction}

Chronic obstructive pulmonary disease (COPD) represents a significant cause of global morbidity and mortality. According to WHO estimates, 65 million people have moderate to severe COPD [1]. Estimates show that COPD will become the third leading cause of death worldwide in 2030. The number of people suffering from COPD in Poland may be as high as 2 million [2]. A significant population of patients is not diagnosed or is diagnosed only at an advanced stage of the disease [2, 3]. Effective

\author{
Corresponding author: \\ Prof. Tadeusz Płusa \\ Faculty of Medicine \\ Lazarski University \\ of Warsaw \\ 43 Świeradowska St \\ 02-662 Warsaw, Poland \\ Phone: +48 225435430 \\ E-mail: respir48@gmail.com
}


management of COPD should include assessment and monitoring of the disease, reducing risk factors, and managing stable COPD and exacerbations. According to the GOLD 2018 guidelines [4], the goal of treating COPD is to relieve symptoms, reduce the frequency and severity of exacerbations and improve exercise tolerance.

In the treatment of stable COPD long-acting $\beta 2$ agonist (LABA) and long-acting muscarinic antagonists (LAMA) significantly improve lung function, dyspnoea, and health status, and reduce exacerbation rates [4]. LABA/LAMA combination therapy increases forced expiratory volume in $1 \mathrm{~s}\left(\mathrm{FEV}_{1}\right)$ and reduces symptoms more effectively in comparison with monotherapy [4]. Treatment of COPD patients with LAMA/LABA combination is more effective than long-acting bronchodilator monotherapy for preventing exacerbations [4, 5].

The dual bronchodilation effect of the fixeddose combination of indacaterol (IND) (LABA) with glycopyrronium (GLY) (LAMA) was examined in a series of studies. In the SHINE study, IND/GLY combination significantly improved trough FEV compared with a single bronchodilator (IND, GLY, tiotropium) and placebo in patients with moderate-to-severe COPD [6]. Results of SHINE [6] and ENLIGHTEN [7] showed that the incidence of adverse events was similar in the IND/GLY and placebo groups. In another study, ILLUMINATE, FEV standardised area under the curve from 0 to $12 \mathrm{~h}$ at week 26 was significantly higher with IND/ GLY compared with salmeterol/fluticasone, with a similar incidence of adverse events between treatment groups [8].

In Poland, access of patients to IND, GLY and dual bronchodilators is well established nowadays. IND and GLY have been reimbursed in Poland since 2014 and a combination of those substances in one device from 2017 [9]. Furthermore, every formulation is available free of charge for patients aged $\geq 75$ years [9]. Patients have greater access to this treatment in routine medical practice.

Research conducted in Poland in 2016 showed that the actual state of treatment differed from the official standards and needs. The LAMA and LABA/LAMA combined treatment therapies were underused. Furthermore, the use of combined medications in one device was not common. Specialists declared that half of the treatments recommended recently by general practitioners required modifications. The medications were administered via a separate inhaler in most cases [10]. Delayed access to medicines limited their implementation in clinical practice. Thus, treatment benefits key to more individualised therapy of COPD [4] could not be fully insured.

Evaluating patient-centred outcomes associated with COPD is likely to play an important role in the future research [11]. To understand the impact of routinely administered treatment with either IND or GLY or both used in combination on patient-reported outcomes, health status and level of dyspnoea were assessed in a population of Polish patients with stable COPD.

\section{Material and methods}

\section{Study design}

It was an observational, non-interventional, prospective, multicentre study in patients with stable COPD initiating treatment with IND and/or GLY as part of routine treatment. The study was conducted in accordance with the Declaration of Helsinki [12] and followed the International Society for Pharmacoepidemiology Good Pharmacoepidemiology Practices Guidelines [13] and STROBE standards [14]. All patients gave written informed consent before entering the study. The study results were described previously for the per-protocol population [15]. Currently, to reflect routine practice of COPD care and frequency of visits, patients missing one of the follow-up visits or having delayed visits were included in the analysis.

The study aimed to evaluate the effect of maintenance treatment with IND and/or GLY on quality of life and level of dyspnoea. The study included patients aged $\geq 18$ years with a diagnosis of COPD with post-bronchodilator $\mathrm{FEV}_{1}$ /forced vital capacity $<0.7$ within 12 months prior to the first visit, with stable disease (no severe COPD exacerbation (exacerbation leading to hospitalization) for $<6$ weeks before the first study visit), and additionally with no prior treatment with either IND or GLY within the previous 3 months. In order to enrol as broad a population of patients as possible, they were excluded only if they had asthma-COPD overlap, were unable to fulfil study demands or if they were participating in another clinical trial.

The decision to initiate treatment with IND and/or GLY was independent of the decision to enrol patients in the study. Patients were treated according to local routine clinical practice. At the initial visit patients started treatment with IND $300 \mu \mathrm{g}$ or GLY $50 \mu \mathrm{g}$ or the combination of IND 150 or $300 \mu \mathrm{g}$ with GLY $50 \mu \mathrm{g}$ and were assigned to respective study groups. Study visits and treatment monitoring procedures were made according to routine clinical practice at participating sites. During study visits quality of life and level of dyspnoea were estimated using the Clinical COPD Questionnaire (CCQ) [16] and the modified Medical Research Council (mMRC) scale [17], respectively. To enable assessment of endpoints in time, the study included two subsequent follow-up visits after around 3 (V2) and 6 months (V3) after the initial visit (V1). To reflect the real-life frequency of out-patient visits, a visit occurring up to 
4.5 months after the initial visit was considered as V2 and the subsequent visit as V3. Investigators were obliged to report all treatment-related and unrelated adverse events.

\section{Statistical analysis}

Patients' characteristics were summarised using the median and range or mean \pm standard deviation (SD) for continuous variables, and counts and percentages for categorical variables. Comparisons between patient characteristics in groups were performed using the Mann-Whitney test or Student's $t$-test depending on the distribution of variables. Results of CCQ and mMRC were presented as the mean and standard deviation. Comparison of CCQ and $\mathrm{mMRC}$ changes in time in each study group was made using the paired Wilcoxon test.

\section{Results}

\section{Patient characteristics}

The study was conducted from May 2015 to June 2016 in 32 centres in Poland. The study included 633 patients, of whom 47 were excluded from the analysis due to lack of possibility of verifying source data. Patients were divided into three groups depending on therapy initiated at baseline (Figure 1, Table I). Over half of patients started treatment with GLY. Smoking history was reported by $92.6 \%$ of patients, and $47.4 \%$ had continued smoking (Table I). $46.6 \%$ of patients experienced exacerbations in the 12 months before study entry. Previous maintenance therapy was used by $28.3 \%$ of patients.

Baseline patient characteristics were not balanced between groups. The $\mathrm{FEV}_{1}$ values varied among the three groups. For patients in the IND/

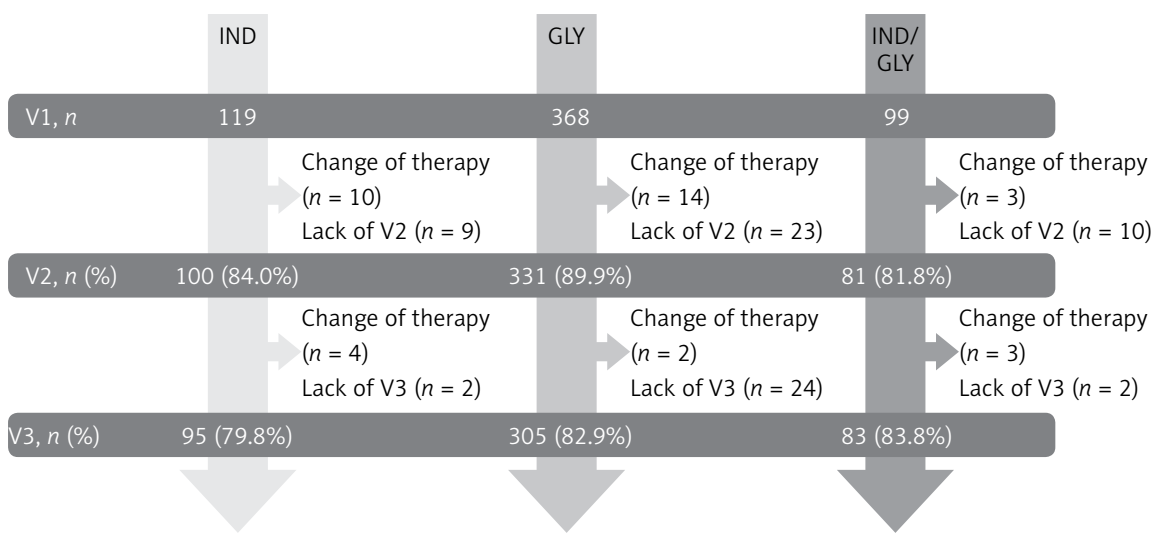

Figure 1. Study flow chart

Table I. Demographics and baseline characteristics of patients participating in the study

\begin{tabular}{|c|c|c|c|c|}
\hline Baseline characteristics & $\begin{array}{c}\text { IND } \\
(n=119)\end{array}$ & $\begin{array}{c}\mathrm{GLY} \\
(n=368)\end{array}$ & $\begin{array}{l}\text { IND/GLY } \\
(n=99)\end{array}$ & $P$-value \\
\hline Age, mean \pm SD [years] & $66.5 \pm 8.5$ & $66.4 \pm 8.8$ & $68.5 \pm 8.3$ & 0.0471 \\
\hline Female gender, $n(\%)$ & $43(36.1)$ & $142(38.6)$ & $35(35.3)$ & 0.5562 \\
\hline \multicolumn{4}{|l|}{ Smoking status, $n(\%)$ : } & \multirow[t]{4}{*}{0.0393} \\
\hline Never smoker & $6(5.0)$ & $35(9.5)$ & $2(2.0)$ & \\
\hline Ex-smoker & $55(46.2)$ & $165(44.8)$ & $45(45.5)$ & \\
\hline Current smoker & $58(48.7)$ & $168(45.7)$ & $52(52.5)$ & \\
\hline $\mathrm{FEV}_{1}{ }^{*}$, mean $\pm \mathrm{SD}[\%]$ & $50.1 \pm 18.4$ & $60.5 \pm 16.6$ & $57.9 \pm 21.3$ & $<0.001$ \\
\hline Patients with moderate exacerbations ${ }^{*}, n(\%)$ & $45(37.8)$ & $127(34.5)$ & $55(55.6)$ & $<0.001$ \\
\hline Patients with severe exacerbations ${ }^{*}, n(\%)$ & $8(6.7)$ & $24(6.5)$ & $13(12.1)$ & 0.0341 \\
\hline $\begin{array}{l}\text { Patients without previous maintenance } \\
\text { treatment }{ }^{* *}, n(\%)\end{array}$ & $22(18.5)$ & $100(27.2)$ & $44(44.4)$ & $<0.001$ \\
\hline $\mathrm{mMRC}$ score, mean $\pm \mathrm{SD}$ & $2.1 \pm 0.9$ & $1.7 \pm 0.9$ & $2.2 \pm 0.8$ & $<0.001$ \\
\hline Total CCQ score, mean \pm SD & $2.2 \pm 0.9$ & $2.1 \pm 1.0$ & $2.6 \pm 1.0$ & $<0.001$ \\
\hline
\end{tabular}

${ }^{*} F E V$ measured/exacerbations occurred 12 months before V1, **based on medications used 6 months before V1; CCQ - Clinical COPD Questionnaire, $M M R C$ - modified Medical Research Council scale. 
GLY group, it was less likely that they had never smoked compared with patients in the GLY group. They were also older, had more moderate and severe exacerbations of COPD, were less likely to have used maintenance treatment before baseline, and had higher baseline CCQ scores compared with patients in the other two groups. Patients in the GLY group had a lower baseline $\mathrm{MMRC}$ score compared with IND and IND/GLY groups (Table I).

Five hundred and twelve patients (87.3\%) attended the second visit (V2), which happened at a median of 3.06 months (range: 1.3-4.4) after the first visit. Eight patients did not participate in V2 but did attend V3, at > 4.5 months after the initial visit. Overall, 483 patients had the third visit (82.4\%) which occurred at a median of 6.10 months (range: $3.7-8.8$ ) after the initial visit (Figure 1). Time intervals between $\mathrm{V} 1$ and $\mathrm{V} 2$, and V2 and V3 were similar ( $p=0.79$; Wilcoxon test, paired samples).

\section{Quality of life}

Patients with a CCQ score $\geq 3$ at baseline consisted of $20.1 \%$ of all patients in IND and GLY groups (24/119 and 74/368, respectively), and $33.3 \%$ (33/99) in the IND/GLY group. The total CCQ score improved (score decrease) between V1 and $\mathrm{V} 3$ in all study groups. The mean CCQ total score \pm SD changed significantly from $2.2 \pm 0.9$ at baseline to $1.5 \pm 0.9$ at 3 months, and to $1.2 \pm 0.9$ at 6 months for patients treated with IND $(p<0.001)$. For patients treated with GLY the mean CCQ score \pm SD decreased significantly from $2.1 \pm 1.0$ at baseline to $1.4 \pm 0.9$ and $1.0 \pm 0.9$ after 3 and 6 months, respectively $(p<0.001)$. In the group of patients treated with IND/GLY the mean CCQ score $2.6 \pm 1.1$ at baseline decreased to $1.6 \pm 1.0$ and $1.3 \pm 1.0$ at 3 and 6 months, respectively ( $p<0.001$ ) (Figure 2). These changes were consistent across symptoms,

$\mathrm{A}_{4}$

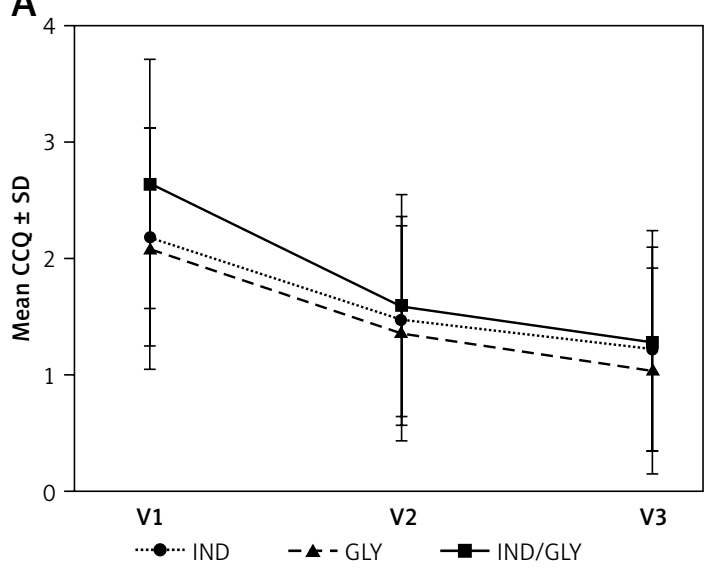

functional, and mental domains of CCQ and were all statistically significant. The percentages of 6-month observation completers who experienced minimal clinically important change (MCIC) of -0.4 points in CCQ [17] were 91.6\% (76/83), 88.4\% (84/95), and $82.6 \%$ (252/305), in IND/GLY, IND, and GLY groups, respectively. Treatment effects in subgroups of patients not receiving previous maintenance treatment and patients changing maintenance treatment or modifying treatment schemes were the same (results not shown).

\section{Impact of treatment on breathlessness}

The proportion of patients with a high level of symptoms, reporting a baseline mMRC score of 2 or more, was 85/99 (85.8\%), 87/119 (73.1\%), and $224 / 368$ (60.8\%) in IND/GLY, IND, and GLY groups, respectively. Level of breathlessness improved at 3- and 6-month follow-up compared to baseline in all study groups. In the group of patients treated with IND, the mean $\mathrm{mMRC} \pm \mathrm{SD}$ decreased from $2.1 \pm 0.9$ at baseline to $1.5 \pm 0.9$ and $1.4 \pm 0.9$ at 3 and 6 months follow-up $(p<0.001)$. Mean mMRC $\pm S D$ changed from $2.1 \pm 0.9$ at baseline to $1.2 \pm 1.0$ at 3 months and remained stable at 6 months follow-up in the group treated with GLY $(p<0.001)$. For patients treated with combination IND/GLY mean MMRC \pm SD decreased from $2.3 \pm 0.8$ at $\mathrm{V} 1$ to $1.6 \pm 0.8$ at $\mathrm{V} 2$ and $1.4 \pm 0.9$ at $\mathrm{V} 3$ $(p<0.001)$ (Figure 2). Treatment effects in subgroups of patients not treated previously with the maintenance treatment and patients changing maintenance treatment or modifying treatment schemes were the same (results not shown).

\section{COPD exacerbations}

Data on baseline frequency of exacerbations that occurred 12 months before $\mathrm{V} 1$ are available

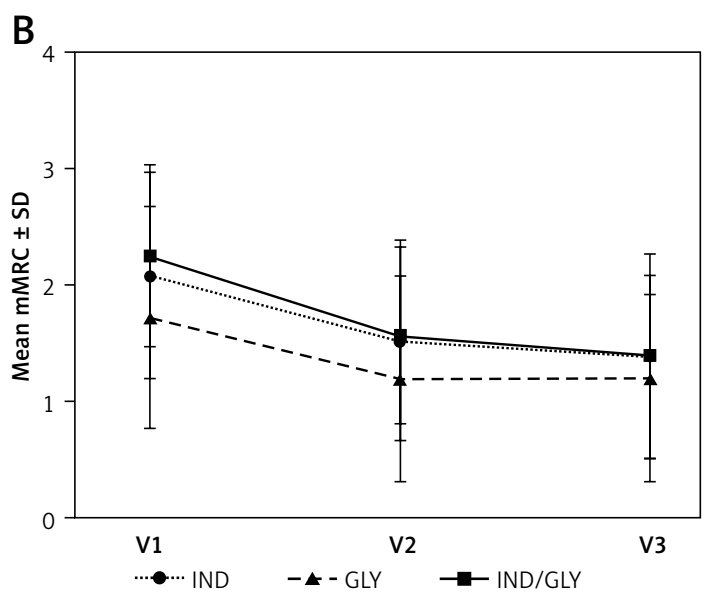

Figure 2. Changes from baseline (V1) to visit 2 (3 months) and to visit 3 (6 months) in total Clinical COPD Questionnaire score (A) and modified Medical Research Council scale (B) in patients treated with indacaterol (IND), glycopyrronium (GLY) and indacaterol and glycopyrronium (IND/GLY). Higher mean Clinical COPD Questionnaire and modified Medical Research Council scale scores indicate worse health status and dyspnoea. Data are mean \pm SD 
in Table I. After 6 months of observation in the IND group $\geq 1$ moderate exacerbation occurred in $18(18.0 \%)$ patients, and in the IND/GLY group in $20(24.1 \%)$ patients. There were no events of severe exacerbation in the above groups. In the GLY group, 45 (13.6\%) patients suffered from $\geq 1$ moderate and $3(1 \%)$ patients from severe exacerbations.

\section{Maintenance treatment}

Each pharmacological treatment used by the patient at 6 months before baseline (V1) and at subsequent visits was categorised into one of five categories: inhaled corticosteroids (ICS), LABA (other than IND), LAMA (other than GLY), rescue medicines, and others. Figure 3 shows the reduction in the number of patients using additional treatments in each of the studied groups between V1 and V3. If the patient was using maintenance treatment at baseline (V1), IND and/or GLY were added or substituted it. Consequently, initiation of IND was a substitution of LABA in most of the cases and at the end of observation $34.7 \%$ of patients were using IND with LAMA. Almost half of the patients who initiated treatment with GLY at
V1 were using it in combination with LABA at V3. Reduction of the use of ICS between V1 and V3 was highest in the group of patients using IND/ GLY - over 5 times fewer patients were using ICS at the end of the study compared with baseline. Around half of patients in each study group used short-acting medicines (Figure 3). At V3, 41.1\%, $31.5 \%$ and $30.1 \%$ of patients were using rescue medicines in IND, GLY, and IND/GLY groups, respectively. Triple combination therapy (LAMA/ LABA/ICS) was used by $19.2 \%$ of patients $(n=93)$ at the end of the study and was highest in the GLY group $(24.2 \%, n=74)$. At the end of the observation $20.0 \%$ and $25.5 \%$ of patients were using the LABA/LAMA combination in IND $(n=19)$ and GLY $(n=78)$ groups, respectively.

\section{Safety}

During the study, in $45(7.7 \%)$ patients 159 adverse events were reported. In 19 patients 68 serious adverse events were reported: in $12 \mathrm{pa}$ tients treated with IND, 4 patients treated with IND and 3 patients treated with IND/GLY. Three patients died: one treated with IND and two with GLY. In 2 patients, the cause of death was myo-

\begin{tabular}{|c|c|c|c|c|c|}
\hline & ICS & LABA & LAMA & $\begin{array}{c}\text { Short-acting } \\
\text { medicines }\end{array}$ & Others \\
\hline \multicolumn{6}{|l|}{ IND } \\
\hline $\mathrm{V} 1^{*}(n=119)$ & $61(51.3 \%)$ & 84 (70.6\%) & $67(53.3 \%)$ & 70 (59.9\%) & $24(20.2 \%)$ \\
\hline V2 $(n=100)$ & 22 (22.0\%) & $2(2.0 \%)$ & $33(33.0 \%)$ & 45 (45.0\%) & $13(13.0 \%)$ \\
\hline V3 $(n=95)$ & 19 (20.0\%) & $3(3.2 \%)$ & $33(34.7 \%)$ & 39 (41.1\%) & $13(13.7 \%)$ \\
\hline \multicolumn{6}{|l|}{ GLY } \\
\hline $\mathrm{V}^{*}(n=369)$ & $133(36.1 \%)$ & 255 (69.3\%) & $82(22.3 \%)$ & 209 (56.9\%) & 27 (7.3\%) \\
\hline V2 $(n=331)$ & 75 (22.7\%) & 167 (50.5\%) & $1(0.3 \%)$ & $100(30.2 \%)$ & $16(4.8 \%)$ \\
\hline V3 $(n=305)$ & 76 (24.9\%) & 152 (49.8\%) & $3(1.0 \%)$ & 96 (31.5\%) & $21(6.9 \%)$ \\
\hline \multicolumn{6}{|l|}{ IND/GLY } \\
\hline $\mathrm{V} 1^{*}(n=99)$ & $32(32.3 \%)$ & 49 (49.5\%) & 21 (21.2\%) & 47 (47.5\%) & 7 (7.1\%) \\
\hline $\operatorname{V2}(n=91)$ & 9 (11.1\%) & $8(9.9 \%)$ & $0(0 \%)$ & 24 (29.6\%) & $9(9.9 \%)$ \\
\hline V3 $(n=93)$ & $5(6.0 \%)$ & $2(2.4 \%)$ & $0(0 \%)$ & 25 (30.1\%) & $9(9.6 \%)$ \\
\hline
\end{tabular}

Figure 3. Change in use of maintenance treatment used before initiation (V1) of indacaterol (IND), glycopyrronium (GLY) and combination therapy of indacaterol and glycopyrronium (IND/GLY) at follow-up (V2 and V3). $\mathrm{N}$ indicates the number of patients in each group. All data are $n$ (\%). Bars show \% of patients using maintenance treatment from a given group in V1, V2 and V3. Medicines were divided into five groups: ICS (beclomethasone, budesonide, ciclesonide, fluticasone, methylprednisolone), LABA (formoterol, salmeterol, vilanterol), LAMA (tiotropium), short-acting medicines (salbutamol, fenoterol, ipratropium) and others (theophylline)

*Medicines used by patients 6 months before. 
cardial infarction, stroke and interstitial changes in the lungs in the course of lymphoma. No cause of death was given for one patient. Mild or moderate adverse events occurred in 37 patients (IND, $n=16$; GLY, $n=18$; IND/GLY, $n=3$ ). The most commonly reported adverse events classified according to the Medical Dictionary of Regulatory Activities were respiratory, thoracic and mediastinal disorders - IND, 34/119 (28.6\%); GLY, 28/368 (7.6\%); IND/GLY; 3/99 (3\%) (e.g., dyspnoea, cough, pleural disorder, respiratory failure), general disorders and administration site conditions - IND, 15/119 (12.6\%); GLY, 13/368 (3.5\%); IND/GLY, 2/99 (2\%) (e.g., chest pain, fatigue), and cardiac disorders - IND, 5/119 (4.2\%); GLY, 8/368 (2.2\%); IND/GLY; 3/99 (3\%) (e.g., cardiac failure, myocardial infarction).

\section{Discussion}

In line with current GOLD recommendations [4] severity assessment in patients with COPD goes beyond lung function evaluation and includes frequency of exacerbations and assessment of symptoms including measures such as CCQ [16] and the $\mathrm{mMRC}$ scale [17]. These measures reflect the overall clinical status, supplement functional test information, and may be more significant to patients' everyday life $[18,19]$.

The studied population comprised patients visiting physicians because of symptoms, and they were either receiving study drugs as first maintenance therapy or treatment intensification. The decline of lung function measured by $\mathrm{FEV}_{1}$ followed the negative impact of COPD on a patient's health status. Quality of life and level of dyspnoea measures reflected the impact of the disease. Dyspnoea is the main symptom of COPD, usually the first reason for seeking medical help and the most important disability factor associated with the disease. In our study $82.1 \%$ of patients had a high level of symptoms of breathlessness with an $\mathrm{mMRC}$ score of 2 or more [4]. Quality of life was seriously compromised in $22.3 \%$ of patients with a CCQ score $\geq 3$, associated with high mortality risk [20]. The study results showed that use of IND and/or GLY improved quality of life and symptoms of breathlessness within 3 months after initiation and the effect was maintained in the 6-month follow-up.

Physicians participating in the study could decide about the type of treatment initiated at V1 based on individual evaluation of patient health status. In groups of patients starting use of IND and GLY, $34 \%$ and $50 \%$ of them were using LAMA/ LABA-based regimens at the end of the study, respectively. Frequent use of GLY with LABA observed in our study is supported by recent results showing that the LAMA/LABA combination of GLY with formoterol caused a greater improvement in quality of life compared to the respective mono-components or placebo in patients with the highest baseline symptom burden [21]. Nevertheless, treatment outcomes achieved in GLY groups should be interpreted taking into account that every fourth patient was using triple therapy at the end of the study.

On the other hand, patients receiving IND/GLY combination in our study had an even higher demand for symptomatic control, compared with those in IND and GLY groups. They were less likely to have used maintenance treatment previously and had a higher frequency of exacerbations, including severe, and worse quality of life compared to groups receiving IND and GLY. Dual bronchodilation with IND/GLY effectively reduced the high burden of the disease and maintained improvement over time.

It has been shown that the IND/GLY combination provided significant, sustained, and clinically meaningful improvements in lung function versus the salmeterol-fluticasone combination, and was also accompanied by significant symptomatic benefit [8]. In our study the use of dual bronchodilation with IND/GLY resulted in significant reduction in the use of ICS, indicating the possibility of treatment regimen simplification and reduction of risks associated with ICS use (e.g., pneumonia and fractures). Experience from a real-life study conducted in Germany showed that ICS withdrawal is possible with no increased risk of exacerbations in patients with COPD managed in primary and secondary care [22]. In addition, use of IND and/ or GLY also reduced the need for use of short-acting medicines in every studied group. These medicines were mainly rescue medicines.

Safety profiles of IND and/or GLY were consistent with those previously reported. No new safety signals have been identified.

It must be stressed that treatment selection has been based on physicians' preference and judgement and this made the comparison between groups rather difficult due to large differences in groups' characteristics. A potential limitation of this study was the lack of standard timelines for assessment, which is common for studies following real-life practice. Assessments were performed according to patients' needs and individual visit schedule to help to decide on further treatment. Despite the fact that information about adverse reactions was rigorously collected during the study, it lacks information about reasons for treatment discontinuation.

The results of the study indicated that use of IND and/or GLY is a reliable therapeutic option for patients with COPD with or without exacerbation history and requiring symptomatic treat- 
ment. LABA, LAMA and their combinations are the backbone of COPD therapy today [4]. Our study supports the use of IND and/or GLY as a preferred treatment option in symptomatic patients with stable COPD, complementing similar data from randomised controlled trials. IND and/or GLY offer significant benefits for patients just starting their therapy and those not obtaining satisfactory results with current treatment. In each case, the decision about use of IND, GLY or dual bronchodilation based on IND/GLY combination depended on physician judgment and assessment of the patient situation. The study results gave information on the patient-reported perspective of IND and/or GLY effectiveness and their use in everyday clinical practice. By improving quality of life and symptoms control, use of IND and/or GLY provides opportunities for treatment regimen simplification in different populations of patients with COPD without compromises for efficacy and safety.

In conclusion, this analysis demonstrated that the use of IND and/or GLY improved quality of life and level of dyspnoea during 6 months of observation of patients with stable, symptomatic COPD. During 6 months of treatment, in each treatment arm, the rate of exacerbations decreased compared to the equivalent period before the baseline visit. The results of the study indicated that use of IND and/or GLY is a reliable therapeutic option for patients with COPD with or without exacerbation history and requiring symptomatic treatment.

\section{Acknowledgments}

This study was sponsored by Novartis Poland. Medical writing support was provided by Ewelina Drelich and Marcin Balcerzak of Farenta with funding from Novartis Poland.

List of the study investigators: Antoszek Emil, Bigus Krzystof, Bujan Jacek, Czerwonko Urszula, Dec-Idziaszek Beata, Drozd-Kołban Lidia, Dworniczak Szymon, Filipek Krzysztof, Hebel Małgorzata, Hetman Anna, Kamińska Teresa, Kiełt-Bień Katarzyna, Kremer Danuta, Kubizna Sylwia, Kuczyńska Kinga, Lisowska Barbara, Ludwin Bożena, Magner Alina, Mróz Robert, Murmyło Marcin, Nowacka-Apiyo Joanna, Polańska-Eisler Anna, Rogozińska Anna, Rulewicz-Warniełlo Mirosława, Rutkowski Dariusz, Rybicka-Liszewska Elżbieta, Szydłowska Grażyna, Trybułowska Wacława, Włodarczyk Robert, Włodarczyk Marcin, Wróbel Krzysztof.

\section{Conflict of interest}

The author declares no conflict of interest.

\section{References}

1. World Health Organization. Chronic respiratory diseases. Burden of COPD. Available at: www.who.int (Accessed July $10^{\text {th }}, 2018$ )
2. Jassem E, Górecka D. Severe and terminal chronic obstructive pulmonary disease. Pneumonol Alergol Pol 2009; 77: 411-6.

3. Śliwiński P, Górecka D, Jassem E, Pierzchała W. Zalecenia Polskiego Towarzystwa Chorób Płuc dotyczące rozpoznawania i leczenia przewlekłej obturacyjnej choroby płuc. Pneumonol Alergol Pol 2014, 82: 227-63.

4. Global Initiative for Chronic Obstructive Pulmonary Lung Disease. Global strategy for the diagnosis, management and prevention of chronic obstructive pulmonary lung disease. 2018 update. Available at: https:// goldcopd.org/ (Accessed July 10 ${ }^{\text {th }}, 2018$ ).

5. Wedzicha JA, Decramer M, Ficker JH, et al. Analysis of chronic obstructive pulmonary disease exacerbations with the dual bronchodilator QVA149 compared with glycopyrronium and tiotropium (SPARK): a randomised, double-blind, parallel-group study. Lancet Respir Med 2013; 1: 199-209.

6. Bateman ED, Ferguson GT, Barnes N, et al. Dual bronchodilation with QVA149 versus single bronchodilator therapy: the SHINE study. Eur Respir J 2013; 42: 1484-94.

7. Dahl R, Chapman KR, Rudolf M, et al. Safety and efficacy of dual bronchodilation with QVA149 in COPD patients: the ENLIGHTEN study. Respir Med 2013; 107: 1558-67.

8. Vogelmeier CF, Bateman ED, Pallante J, et al. Efficacy and safety of once-daily QVA149 compared with twice-daily salmeterol-fluticasone in patients with chronic obstructive pulmonary disease (ILLUMINATE): a randomised, double-blind, parallel group study. Lancet Respir Med 2013; 1: 51-60.

9. Ministerstwo Zdrowia. Obwieszczenie Ministra Zdrowia w sprawie wykazu refundowanych leków, środków spożywczych specjalnego przeznaczenia żywieniowego oraz wyrobów medycznych. Available at: https://www. gov.pl/zdrowie/obwieszczenia-ministra-zdrowia-lista-lekow-refundowanych (Accessed July 10 ${ }^{\text {th }}, 2018$ ).

10. Miłkowska-Dymanowska J, Białas AJ, Górski P. Selected aspects of medical care for patients with asthma and chronic obstructive pulmonary disease (COPD) in Poland. Adv Respir Med 2017; 85: 179-85.

11. van der Molen T, Cazzola M. Beyond lung function in COPD management: effectiveness of LABA/LAMA combination therapy on patient-centred outcomes. Prim Care Respir J 2012; 21: 101-8.

12. Declaration of Helsinki; 2008.

13. International Society for Pharmacoepidemiology. Guidelines for Good Pharmacoepidemiology Practices (GPP); June 2015.

14. Vandenbroucke JP, von Elm E, Altman DG, et al. Strengthening the Reporting of Observational Studies in Epidemiology (STROBE): explanation and elaboration. Int J Surg 2014; 12: 1500-24.

15. Płusa T. Evaluation of effect of indacaterol (Onbrez) and/or glycopyrronium (Seebri) treatment on Quality of Life of COPD patients in medical practice in Poland observational study (OSQO). Pol Merkur Lekarski 2017; 43: 158-62.

16. van der Molen T, Willemse BW, Schokker S, ten Hacken $\mathrm{NH}$, Postma DS, Juniper EF. Development, validity and responsiveness of the Clinical COPD Questionnaire. Health Qual Life Outcomes 2003; 1: 13.

17. Bestall JC, Paul EA, Garrod R, Garnham R, Jones PW, Wedzicha JA. Usefulness of the Medical Research Council (MRC) dyspnoea scale as a measure of disability in patients with chronic obstructive pulmonary disease. Thorax 1999; 54: 581-6. 
18. Kocks JWH, Tuinenga MG, Uil SM, van den Berg JWK, Ståhl E, van der Molen T Health status measurement in COPD: the minimal clinically important difference of the clinical COPD questionnaire. Respir Res 2006; 7: 62.

19. Jones PW, Kaplan RM. Methodological issues in evaluating measures of health as outcomes for COPD. Eur Respir J Suppl 2003; 41: 13-8.

20. Sundh J, Janson C, Lissper K, Montgomery S, Ställberg B. Clinical COPD Questionnaire score (CCQ) and mortality. Int J Chron Obstruct Pulmon Dis 2012; 7: 833-42.

21. Martinez FJ, Rabe KF, Ferguson GT, et al. Efficacy and safety of glycopyrrolate/formoterol metered dose inhaler formulated using co-suspension delivery technology in patients with COPD. Chest 2017; 151: 340-57.

22. Vogelmeier $C$, Worth $H$, Buhl $R$, et al. "Real-life" inhaled corticosteroid withdrawal in COPD: a subgroup analysis of DACCORD. Int J Chron Obstruct Pulmon Dis 2017; 12 487-94. 